\title{
Characteristics of Flame and Heat Release Under Flash Boiling Condition at Varying Injection Timing
}

\author{
Haotian $\mathrm{Xu}^{1}$, Zhe Sun ${ }^{1}$, Xuesong Li ${ }^{1}$, David L.S. Hung ${ }^{1,2}$, Min Xu*1 \\ ${ }^{1}$ School of Mechanical Engineering, Shanghai Jiao Tong University, Shanghai, China \\ ${ }^{2}$ University of Michigan-Shanghai Jiao Tong University Joint Institute, Shanghai Jiao Tong \\ University, Shanghai, China
}

\begin{abstract}
Flash boiling spray is a multiphase flow that constantly generates vapor bubbles inside the liquid spray. Compared with sub-cooled spray, the spray atomization effect can be significantly improved. Therefore, the flash boiling spray has been a research hotspot in recent years. In this paper, to explore the effect of flash boiling on the combustion process at different injection timing, a visualized combustion analysis of flash boiling spray and sub-cooled spray combustion at different injection timing is carried out by using an optical engine and through cylinder pressure and optical diagnostic techniques.

The results reveal that the combustion performance using flash boiling sprays is superior to that using sub-cooled sprays under different injection timing. Flash boiling atomization can usually increase the flame velocity during flame generation and development, and improve the turbulence of flame. In addition, the flash boiling spray leads to a higher propagation rate of flame and higher heat release rate during combustion.
\end{abstract}

\section{Keywords}

Flash boiling spray; Combustion; Heat release; Flame propagation rate; GDI optical engine

\section{Introduction}

Gasoline direct injection (GDI) engine is increasingly used because of its higher combustion efficiency and lower fuel consumption. However, increased particulate emissions caused by spray wall interaction can hardly be controlled by any optimization of the engine. Flashing atomization is a potential alternative for high-pressure injection in direct injection gasoline engines because it can produce thinner droplets and stronger evaporation at low injection pressure [1-3].

Flash boiling spray has been considered as a promising way to enhance the mixing of fuel and air as well as reduce the interaction between impinging walls. With the increase of the corresponding fuel temperature, the phase change phenomenon of microburst and flash boiling at the instant of injection can effectively enhance the atomization and liquid droplet evaporation, which can not only reduce the possibility of the formation of the wall film, but also increase the resistance in the spray propagation process, reduce the penetration distance, and enhance the mixing of the fuel and the air [4-9]. The more homogeneous fuel and air mixing can effectively optimize the combustion process. The study of related flash boiling spray combustion confirms that the development of flash boiling spray combustion system has great potential in improving fuel and air mixing, increasing lean combustion rate, and improving thermal efficiency [10-14].

However, the combustion characteristics vary under different engine conditions. For instance, early injection as the piston approaches the top dead center (TDC) would produce excess impingement fuel films that would lead to undesirable pool fires; while late injection would limit the residual time of the spray in the cylinder so that spray evaporation duration is shortened. The overall combustion efficiency and emission performance rely on all different engine conditions combined based on a series of different combustion mechanisms, which should be 
analyzed if the impact of flash boiling spray combustion is to be illustrated. To achieve such goals, in this work, we literately used various fuel injection timing (although they might not be completely applicable in actual engine applications) to analyze the influence of flash boiling sprays.

In this paper, in order to explore the effect of flash boiling on the combustion process at different injection timing, a visualized combustion analysis of flash and sub-cooled spray combustion at different injection timing is carried out by using an optical engine and through cylinder pressure and optical diagnostic techniques.

\section{Experimental Setup}

In our research, we used a single-cylinder GDI optical engine, as shown in Figure 1. It is a single-cylinder four-stroke spark-ignition engine customized from a 2.0L GM engine. Engine specifications are summarized in Table 1. And the main test instrument used in this research is listed in Table 2. To observe the flame inside the cylinder, a quartz window was inserted in the piston. Therefore, through the reflection of the 45-degree mirror, the bottom-view of flame can be seen outside the engine. The high-speed color camera (NAC HX-5E) equipped with $50 \mathrm{~mm} \mathrm{f} / 1.4$ lens (Zeiss) then recorded the flame with $6 \mathrm{kHz}$ (equivalent to 1 frame $/{ }^{\circ} \mathrm{CA}$ ) for flame images.

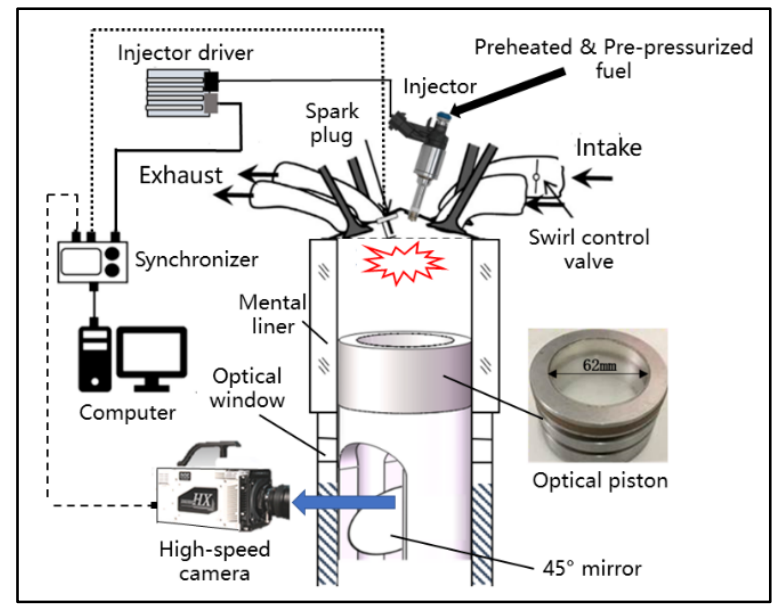

Figure 1..Optical engine experimental layout

The fuel was pressurized in advance, then heated by heating type. And the temperature of fuel was measured and controlled by a thermocouple. Though previous research, it is reported that the ambient-to-saturation pressure ratios $(\mathrm{Pa} / \mathrm{Ps})$ of sub-cooled and flare flash boiling sprays were located in regions $(>1)$ and $(<0.3)$ respective. Consequently, two typical conditions of fuel under $41 \mathrm{kPa}$ back intake pressure are selected. One represented the subcooled condition, the fuel temperature is $30^{\circ} \mathrm{C}$, and the fuel pressure is $10 \mathrm{MPa}$. Another represented the condition of flash boiling, the fuel temperature is $120^{\circ} \mathrm{C}$, and the fuel pressure is also $10 \mathrm{MPa}$. And as for the liner of the optical engine, this research used a metal liner. Furthermore, a combustion analyzer (Kibox type 2893A) and a pressure sensor (Kistler 6125A) were used for combustion characteristic and cylinder pressure measurement, also shown in Table 2.

To study the effect of flash boiling spray on combustion characteristics at different injection timing, we selected three different fuel injection timing including 180bTDC, 300bTDC, and $350 \mathrm{bTDC}$. Under the injection timing of $180 \mathrm{bTDC}$, the residual atomization time of spray is 
relatively short, resulting in insufficient evaporation of fuel. Nevertheless, owing to the top of the piston is very far away from the fuel injection at this time, the combustion deterioration related to piston wetting is not obvious. Under the injection timing of $350 \mathrm{bTDC}$, the remaining atomization time of the spray will be longer, so the fuel evaporation will be more complete, but the piston is very close to the fuel spray, so the phenomenon of spray impinging on the piston will become more obvious. The injection timing of 300bTDC is a compromise between the first two cases, which has a moderate spray atomization time and spray-wall interaction. Therefore, the above three injection timing conditions represent early injection, late injection, and moderate injection respectively. Under the above experimental conditions, this study is expected to explore the effect of flash boiling on combustion at different injection timing.

Table 1 - Optical engine specifications

\begin{tabular}{l|l}
\hline Parameter & Specification \\
\hline Bore & $86 \mathrm{~mm}$ \\
Stroke & $94.6 \mathrm{~mm}$ \\
Con-rod length & $160 \mathrm{~mm}$ \\
Displacement & $0.549 \mathrm{~L}$ \\
Compression ratio & $11.0: 1$ \\
Fuel & Iso-octane \\
Intake timing (IVO/IVC) & $366 / 114^{\circ}$ bTDC Firing \\
Exhaust timing (EVO/EVC) & $131 / 372^{\circ}$ aTDC Firing \\
Coolant/oil temperature & $60^{\circ} \mathrm{C}$ \\
Engine speed & $1000 \mathrm{rpm}$ \\
Injection pressure & $10 \mathrm{MPa}$ \\
Nozzle & $0.13 \mathrm{~mm}$ (Diameter), L/D = 2 \\
Start of injection & $350 \mathrm{bTDC}, 300 \mathrm{bTDC}, 180 \mathrm{bTDC}$ \\
Spark timing & $30 \mathrm{bTDC}$ \\
Fuel temperature & $30^{\circ} \mathrm{C}, 120^{\circ} \mathrm{C}$ \\
Injection duration & $1200 \mu \mathrm{s}$ \\
Equivalent ratio & Stoichiometric
\end{tabular}

Table 2 - Test instrument specifications

\begin{tabular}{l|l}
\hline Equipment & Specification \\
\hline Engine test bench & AVL List $\mathrm{GmbH}, 58 \mathrm{kw}, 180 \mathrm{Nm}, 8000 \mathrm{r} / \mathrm{min}$ \\
Combustion analysis & Kibox type 2893A \\
High-speed color camera & NAC HX-5E \\
Lens & Zeiss $50 \mathrm{~mm} \mathrm{f} / 1.4 \mathrm{D}$ \\
Pressure sensor & Kistler $6125 \mathrm{~A}$
\end{tabular}

\section{Results and Discussion}

Figure 2 depicts the flame area ratio at different injection timing under sub-cooled and flash boiling conditions. The flame area ratio is defined as the ratio between the flame area and the 
optical access window area. It can be seen from the flame area ratio that it increases from $30^{\circ} \mathrm{CA}$ aTDC to $30^{\circ} \mathrm{CA}$ aTDC, which represents the process of flame generation and propagation. From $30^{\circ} \mathrm{CA}$ aTDC to $80^{\circ} \mathrm{CA}$ aTDC, the flame ratio decreases, which represents the stage of flame extinction. Therefore, to analyze the formation and development of flame, this study selected the apparent flame velocity at different injection timing under flash boiling and sub-cooled condition between $-30^{\circ} \mathrm{CA}$ aTDC and $30^{\circ} \mathrm{CA}$ aTDC for analysis, as shown in Figure 4.
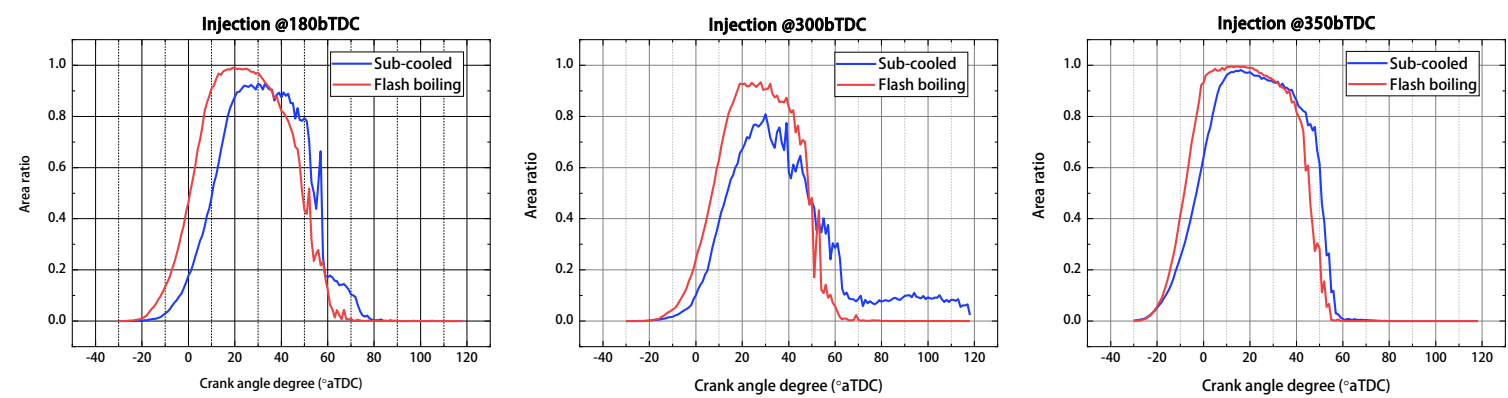

Figure 2.. Variation of flame area ratio under different injection conditions

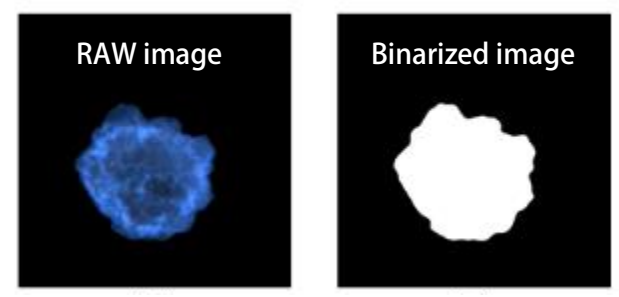

Figure 3. Sketch of flame image postprocessing

The calculation of the apparent flame velocity is through image processing, as shown in Figure 3.First, the flame area was calculated by counting white pixels in the binarized flame image. The flame was equivalent to a circle, and the radius of the circle was calculated by the area, then the derivative of the radius with time was the apparent flame velocity.
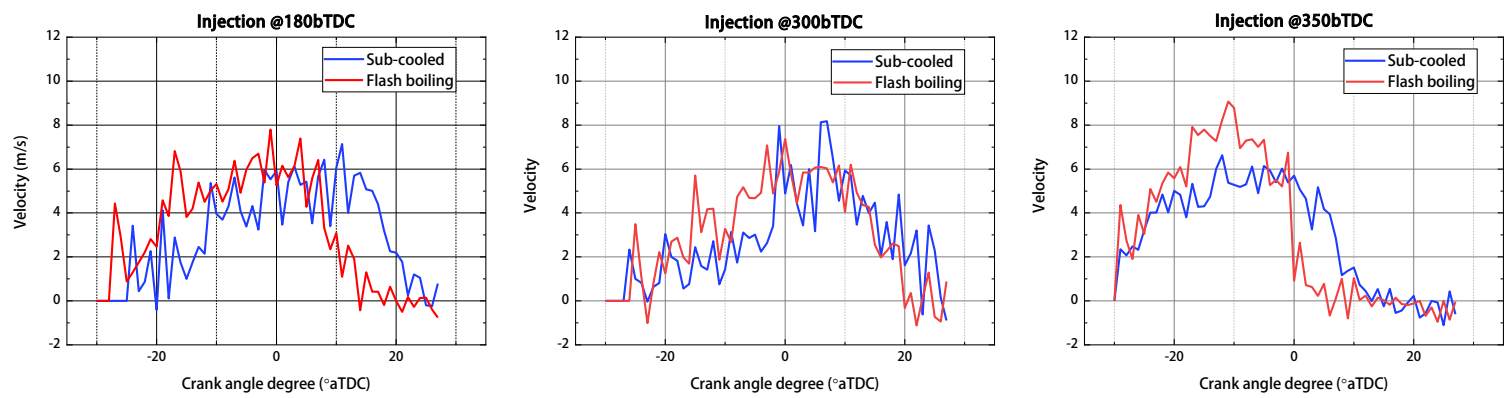

Figure 4.. Variation of velocity under different injection conditions

From the aspect of flame area ratio, the flame area under the flash boiling condition at three different injection timing develops faster than that under the sub-cooled condition and has a larger flame area. The angle of the flame area reaching the peak under flash boiling and subcooled conditions at each injection timing is shown in Table 3. 
Table 3 - Flame area ratio peak angle under different injection conditions

\begin{tabular}{l|lll}
\hline Injection timing & Fuel temperature $\left({ }^{\circ} \mathrm{C}\right)$ & \left.${\text { Peak angle }\left({ }^{\circ}\right)}\right)$ & Decrease (\%) \\
\hline \multirow{2}{*}{ 180bTDC } & 30 & 60 & $22.45 \%$ \\
& 120 & 49 & \\
$300 \mathrm{bTDC}$ & 30 & 60 & $22.45 \%$ \\
& 120 & 49 & \\
$350 \mathrm{bTDC}$ & 30 & 46 & $9.524 \%$
\end{tabular}

It can be seen that when the injection timing at 180 CAD bTDC and 300 CAD bTDC, the time reaching the peak flame area under the flash boiling condition is significantly shorter than that under the sub-cooled condition, up to $22.45 \%$, and it is also slightly shorter under 350 CAD bTDC. When the injection timing is at 350 CAD bTDC, the difference of the maximum flame area between the sub-cooled spray and the flash boiling spray combustion decreases, which means that longer fuel evaporation and mixing time can enhance and stabilize the combustion. It can also be seen from Figure $\mathbf{4}$ and Table $\mathbf{4}$ that the indicated flame velocity under the condition of flash boiling is higher than that under the condition of sub-cooled, which is consistent with the conclusion obtained from the flame area ratio.

Table 4 - Average velocity under different injection conditions

\begin{tabular}{l|llc}
\hline Injection timing & Fuel temperature $\left({ }^{\circ} \mathrm{C}\right)$ & Average velocity $(\mathrm{m} / \mathrm{s})$ & Increase $(\%)$ \\
\hline \multirow{2}{*}{ 180bTDC } & 30 & 3.074958 & $2.698 \%$ \\
& 120 & 3.157928 & \\
$300 \mathrm{~b} T D C$ & 30 & 2.788264 & $10.286 \%$ \\
& 120 & 3.075066 & \\
$350 \mathrm{~b}$ TDC & 30 & 2.977415 & $4.1765 \%$
\end{tabular}

The calculation and analysis of the flame fractal dimension based on the flame image are essential to understand the flame structure and assess its combustion quality [15-17]. the fractal dimension can be exploited as a measurement of the geometric roughness and complexity of the flames. In n-dimensional Euclidean space, box-counting based fractal dimension of a bounded fractal set is defined as

$$
D=\frac{\log \left(N_{r}\right)}{\log (1 / r)}
$$

where $N_{r}$ is the minimum number of boxes at size $r$ that are required to cover the bounded fractal set which can be chaotic curves in a plane or an irregular surface in three-dimensional space.

Because the fractal dimension is related to the fold of flame surface in the shooting angle, and the fold scale of the flame surface is one of the evaluation factors of combustion turbulence, the fractal dimension can be used as the evaluation method of combustion turbulence under certain conditions. In this research, the evaluation of the fractal dimension of the flame edge 
based on the edge image was conducted through the box-counting approach. And the fractal dimension of the premixed flame region was calculated by the three-dimensional box-counting method.
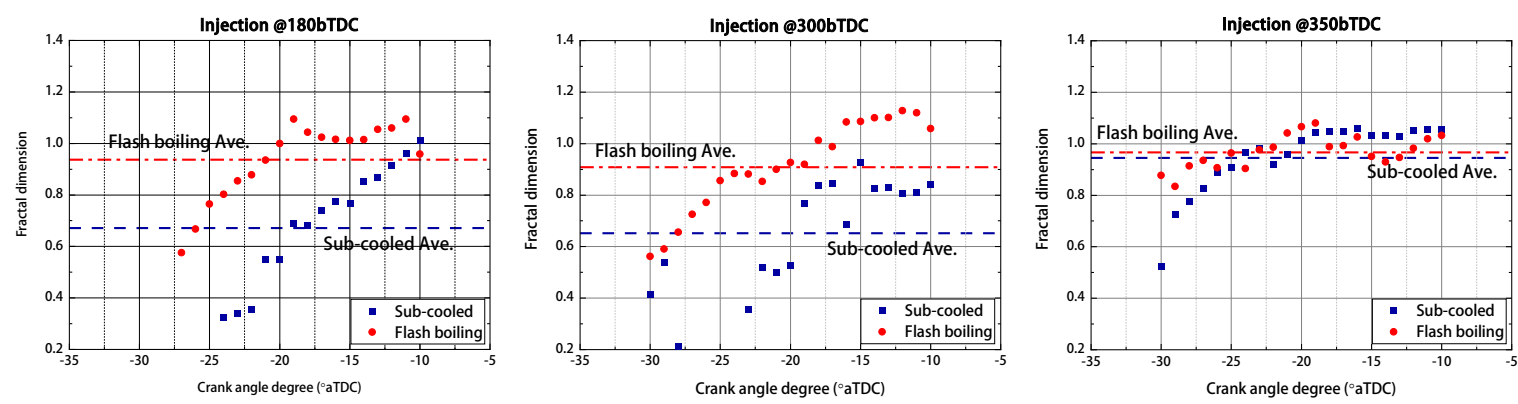

Figure 5.. Variation of flame edge fractal dimension under different injection conditions

Figure 5 depicts the fractal dimension of the flame edge at different injection timing under flash boiling and sub-cooled condition in the flame development stage, from which we can find that the fractal dimension of the flash boiling condition under three injection timing is higher.

Table 5 calculates the average fractal dimension under flash boiling and sub-cooled conditions at different injection timing, which also shows that the flame turbulence is higher under the condition of flash boiling We found that the fractal dimension of the flash boiling condition increases more obviously at $180 \mathrm{bTDC}$ and $300 \mathrm{bTDC}$ injection timing, and the reason here is the same as that mentioned above. When the injection timing is at $350 \mathrm{bTDC}$, the evaporation and mixing time of fuel is longer, and the difference between the effects of flash boiling and sub-cooled conditions on fuel-air mixing is smaller.

Table 5 - Average edge fractal dimension under different injection conditions

\begin{tabular}{|c|c|c|c|}
\hline Injection timing & Fuel temperature $\left({ }^{\circ} \mathrm{C}\right)$ & Ave. edge fractal dimension & Increase (\%) \\
\hline \multirow{2}{*}{ 180bTDC } & 30 & 0.670788 & \multirow{2}{*}{$28.32 \%$} \\
\hline & 120 & 0.93585 & \\
\hline \multirow{2}{*}{ 300bTDC } & 30 & 0.651065 & \multirow{2}{*}{$28.29 \%$} \\
\hline & 120 & 0.907912 & \\
\hline \multirow{2}{*}{ 350bTDC } & 30 & 0.944702 & \multirow{2}{*}{$2.20 \%$} \\
\hline & 120 & 0.965993 & \\
\hline
\end{tabular}

To calculate the fractal dimension of premixed flame, the HSV model is used in this study. The wavelength-related information is extracted from the domain of interest by the HSV model and stored in the hue part. In previous studies, it is found that for the hue part, 0 to 90 represents the diffusion flame area, 118 to 252 represents the premixed flame area, and 300 to 360 represents the near-infrared flame area [18]. Therefore, we use the HSV model to extract the premixed flame region in the flame image and calculate the fractal dimension. 

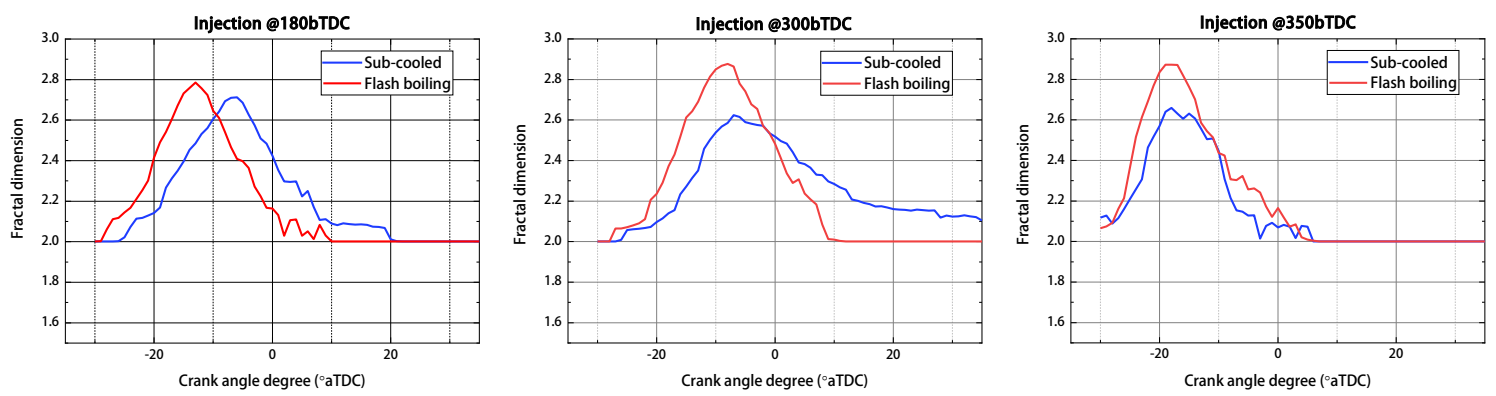

Figure 6.. Variation of premixed flame region fractal dimension under sub-cooled and flash boiling conditions different injection conditions

Figure 6 shows the calculated fractal dimension of the premixed flame region under flashing boiling and sub-cooled condition at different injection timing. It can be seen from the figure that the premixed flame mainly occurs between $-30^{\circ} \mathrm{CA}$ aTDC and $20^{\circ} \mathrm{CA}$ aTDC, and the peak value of the fractal dimension of the premixed flame region under flashing boiling condition is larger than that under sub-cooled condition, and the time to reach the peak value is shorter. It shows that the premixed flame develops faster and the turbulence is higher under the condition of flash boiling. Moreover, comparing the flame velocity in Figure $\mathbf{4}$ with the fractal dimension of the premixed region in Figure 6, it can be found that the time when the flame velocity decreases under the condition of flash boiling corresponds to the time when the fractal dimension of premixed flame decreases to 2.0 . This indicates that the diffusion flame velocity is lower under the condition of flash boiling than that under the condition of sub-cooled, however, the premixed flame velocity is higher.

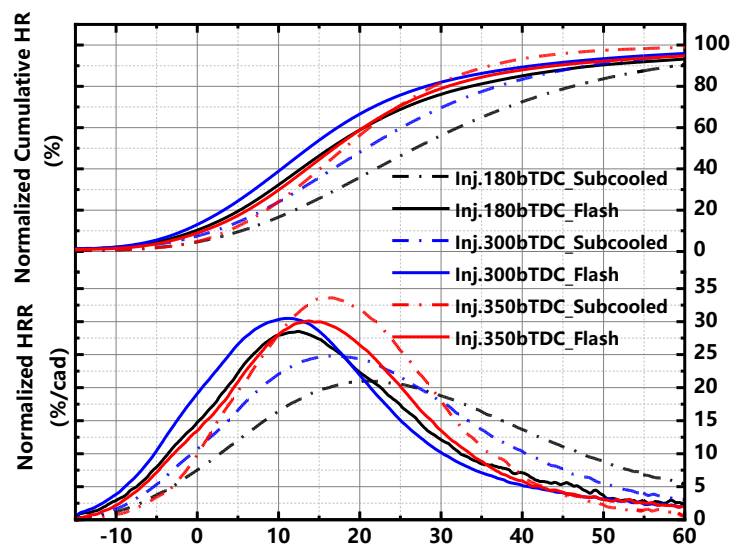

Figure 7.. Variation of HR and HRR under different injection conditions

Figure 7 gives the cumulative HR (heat release) and instantaneous HRR (heat release rate) of flash boiling spray and sub-cooled spray combustion at different injection timing. It can be seen from the cumulative heat release comparison that besides the 350bTDC injection timing, the flash boiling spray has a larger cumulative heat release and the final cumulative heat release during the whole combustion process. From the data of CA50 in Table 6, it can be seen that the CA50 under flash boiling condition is ahead of that under the sub-cooled condition at all injection timing, and at the injection timing of 180bTDC and 300bTDC are ahead of $38.81 \%$ and $35.01 \%$ respectively. This shows that flash boiling spray combustion can release more heat and have a more full combustion effect. From the instantaneous heat release rate, we can see more clearly that the maximum instantaneous heat release rate of flash boiling spray is higher (except for 350bTDC injection timing), the instantaneous heat release peak phase is earlier, and has a faster exothermic speed. This makes more fuel 
release heat at a faster burning rate in the process of engine expansion, so as to improve the function conversion. The reason why the injection timing of $350 \mathrm{bTDC}$ does not conform to the above conclusion is that under this condition, the atomization and mixing time of the fuel is longer, so the promotion effect of flash boiling on fuel-air mixing is not strong.

Table 6 - CA50 under different injection conditions

\begin{tabular}{l|lll}
\hline Injection timing & Fuel temperature $\left({ }^{\circ} \mathrm{C}\right)$ & CA50 $\left({ }^{\circ}\right.$ aTDC $)$ & Decrease $(\%)$ \\
\hline \multirow{2}{*}{ 180bTDC } & 30 & 26.8 & $38.81 \%$ \\
& 120 & 16.4 & \\
$300 \mathrm{bTDC}$ & 30 & 20.8 & $35.10 \%$ \\
& 120 & 13.5 & \\
$350 \mathrm{bTDC}$ & 30 & 18.1 & $7.18 \%$
\end{tabular}

Figure 8 shows the heat map of flame distribution in sub-cooled and flash boiling spray at different injection timing. This graph shows the probability of flame existence, which proves the repeatability of the flame propagation and combustion velocity results discussed earlier. At the same injection timing, the flame propagation speed of flash boiling spray is faster and the duration of the flame is shorter. In Figure 9, a relatively complete moment of flame development under each working condition is selected, and the proportion of the area with flame occurrence probability greater than $90 \%$ in the whole flame occurrence area at this moment is counted. It is found that under the flash boiling condition the area ratio of more than $90 \%$ probability is larger at the same injection timing, which indicates that the combustion stability of flash boiling spray is better.

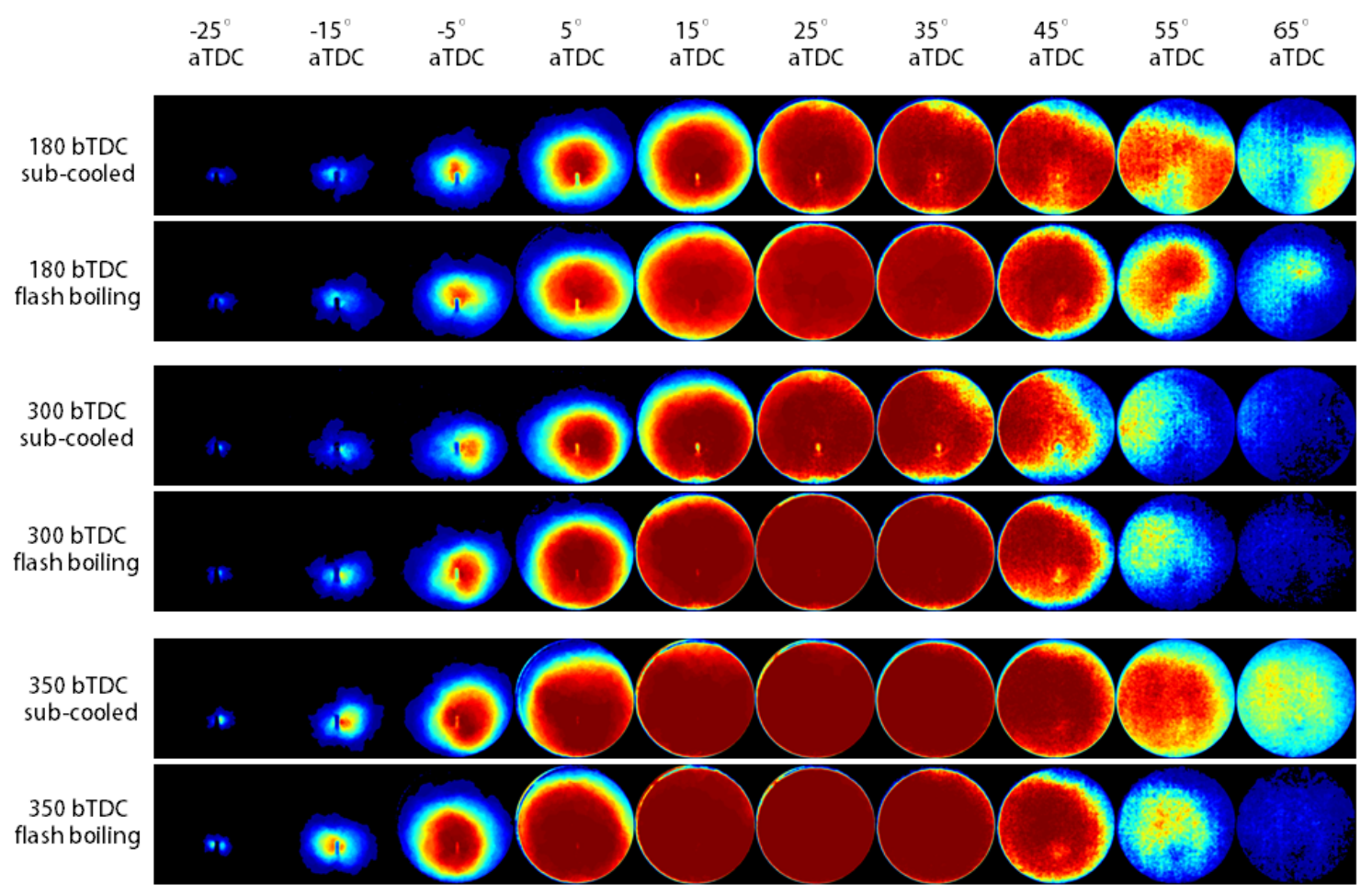

Figure 8.. Variation of heatmap under different injection conditions 


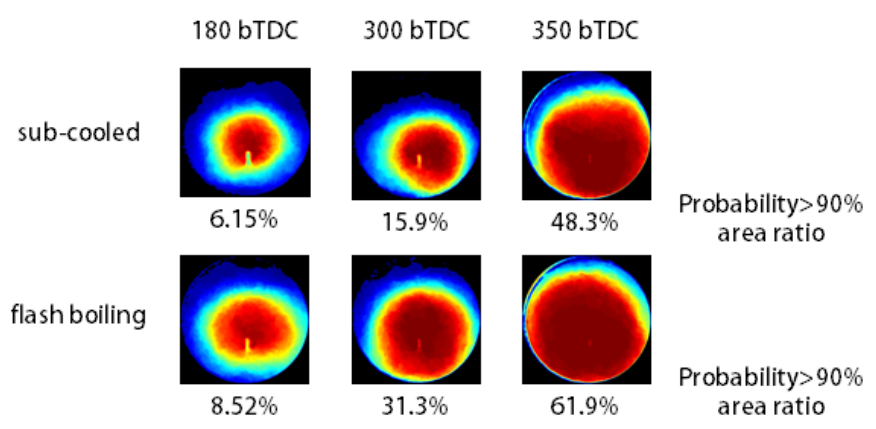

Figure 9.. Probability above $90 \%$ area ratio at $5^{\circ}$ aTDC under different conditions

\section{Conclusions}

In this work, we used an optical engine to explore the flash boiling combustion performance of the gasoline direct injection device setting. Different fuel injection schemes were tested to analyze the effects of flash spray on combustion and heat release at different injection timing. Several conclusions can be drawn from the experiment:

1) Under the experimental conditions introduced in this study, flash boiling atomization can usually increase the flame velocity during flame generation and development. In general, the average flame velocity was developed by $4.1765 \%, 10.286 \%$, and $2.698 \%$; the peak area time of flame was reduced by $9.524 \%, 22.45 \%$, and $22.45 \%$ under early, intermediate and late injection timing.

2) From the analysis of fractal dimension, it can be seen that flash boiling atomization can improve the turbulence of flame. Under the early, intermediate, and late injection timing, the fractal dimension of flame edge increases by $2.20 \%, 28.32 \%$, and $28.29 \%$. Moreover, through the analysis of the fractal dimension of the premixed flame region extracted by the HSV model, it can be seen that the turbulence of premixed flame is higher and the development of premixed flame is faster under the condition of flash boiling.

3) Flash boiling spray combustion can release more heat, have faster exothermic speed, and have a more full combustion effect. Under the early, intermediate, and late injection timing, the combustion CA50 is advanced by $7.18 \%, 38.81 \%$, and $35.10 \%$.

4) From the heat map analysis of the flame image, it can be found that the flame of the flash boiling spray develops faster and the flame stability is better.

\section{Nomenclature}

aTDC after top dead center

$H R R$ heat release rate [\%]

$H R$ heat release [\%/cad]

CA Crank angle degree

\section{References}

[1] Li, Y., Guo, H., Zhou, Z., Zhang, Z., Ma, X., and Chen, L., 2019, "Spray morphology transformation of propane, n-hexane and iso-octane under flash-boiling conditions," Fuel, 236, pp. 677-685.

[2] Li, Y., Guo, H., Ma, X., Qi, Y., Wang, Z., Xu, H., and Shuai, S., 2018, "Morphology analysis on multi-jet flash-boiling sprays under wide ambient pressures," Fuel, 211, pp. 38-47.

[3] Li, X., Yang, S., Li, T., Hung, D. L. S., and Xu, M., 2019, "Investigations on near-field atomization of flash boiling sprays for gasoline direct injection related applications," Fuel, 257, p. 116097. 
[4] Xu, Q., Pan, H., Gao, Y., Li, X., and Xu, M., 2019, "Investigation of two-hole flash-boiling plume-to-plume interaction and its impact on spray collapse," International Journal of Heat and Mass Transfer, 138, pp. 608-619.

[5] Zhang, G., Xu, M., Zhang, Y., Zhang, M., and Cleary, D., 2013, "Macroscopic characterization of flash-boiling multihole sprays using planar laser-induced exciplex fluorescence. Part II: Cross-sectional spray structure," Atomization and Sprays, 23, pp. 265278.

[6] Zhang, G., and Hung, D. L. S., 2015, "Temporal investigations of transient fuel spray characteristics from a multi-hole injector using dimensionless analysis," Experimental Thermal and Fluid Science, 66, pp. 150-159.

[7] Bowditch, F. W., 1961, "A New Tool for Combustion Research A Quartz Piston Engine," SAE International.

[8] Chapman, E., Davis, R. S., Studzinski, W., and Geng, P., 2014, "Fuel Octane and Volatility Effects on the Stochastic Pre-Ignition Behavior of a 2.0L Gasoline Turbocharged DI Engine," SAE International.

[9] Steeper, R. R., and Stevens, E. J., 2000, "Characterization of Combustion, Piston Temperatures, Fuel Sprays, and Fuel-Air Mixing in a DISI Optical Engine," SAE International. [10] Stevens, E., and Steeper, R., 2001, "Piston Wetting in an Optical DISI Engine: Fuel Films, Pool Fires, and Soot Generation," SAE Int. J. Engines, 110, pp. 1287-1294.

[11] Wang, Z., Li, Y., Guo, H., Wang, C., and Xu, H., 2018, "Microscopic and macroscopic characterization of spray impingement under flash boiling conditions with the application of split injection strategy," Fuel, 212, pp. 315-325.

[12] Yang, J., Xu, M., Hung, D. L. S., Wu, Q., and Dong, X., 2017, "Influence of swirl ratio on fuel distribution and cyclic variation under flash boiling conditions in a spark ignition direct injection gasoline engine," Energy Conversion and Management, 138, pp. 565-576.

[13] Yang, J., Dong, X., Wu, Q., and Xu, M., 2019, "Effects of enhanced tumble ratios on the in-cylinder performance of a gasoline direct injection optical engine," Applied Energy, 236, pp. 137-146.

[14] Dong, X., Yang, J., Hung, D. L. S., Li, X., and Xu, M., 2019, "Effects of flash boiling injection on in-cylinder spray, mixing and combustion of a spark-ignition direct-injection engine," Proceedings of the Combustion Institute, 37(4), pp. 4921-4928.

[15] Chatakonda, O., Hawkes, E. R., Aspden, A. J., Kerstein, A. R., Kolla, H., and Chen, J. H., 2013, "On the fractal characteristics of low Damköhler number flames," Combustion and Flame, 160(11), pp. 2422-2433.

[16] Yi, Y., Geng, L., and Jing, G., 2012, "Experimental study on the fractal characteristic of methane explosion flame," Safety Science, 50(4), pp. 679-683.

[17] Denet, B., 2000, "Fractal Dimension of Turbulent Premixed Flames for Different Turbulence Spectra," Combustion Science and Technology, 159(1), pp. 305-314.

[18] Yang, J., Ma, Z., and Zhang, Y., 2019, "Improved colour-modelled $\mathrm{CH}^{*}$ and C2* measurement using a digital colour camera," Measurement, 141, pp. 235-240. 